\title{
Nostocarboline: Isolation and Synthesis of a New Cholinesterase Inhibitor from Nostoc 78-12A
}

\section{Supporting Information}

Paul G. Becher, Julian Beuchat, Karl Gademann* and Friedrich Jüttner*

Limnological Station, Institute of Plant Biology, Seestr. 187,

8802 Kilchberg, Switzerland

and

Laboratorium für Organische Chemie der

Eidgenössischen Technischen Hochschule Zürich

ETH Hönggerberg, 8093 Zürich, Switzerland

\section{Table of Contents}

Modified procedure of 6-Cl-norharmane

Figure S-1: Nostocarboline (1)

Figure S-2: Nostocarboline iodide (1a)

S-4

Figure S-3: Nostocarboline, mixture of synthetic and natural samples

Figure S-4: Nostocarboline (1)

S-6

Figure S-5: Nostocarboline iodide (1a)

S-6

Figure S-6: Nostocarboline, mixture of synthetic and natural samples

S-7

Figure S-7: Nostocarboline (1a), 1H NMR and HSQC spectra

S-8 


\section{6-Cl-norharmane.}

Modification of the procedure by Nakano, K.; Suyama, K.; Fukazawa, H.; Uchida, M.; Wakabayashi, K.; Shiozawa, T.; Terao, Y. Mutation Research 2000, 470, 141-146.

Norharmane (600 mg, $3.6 \mathrm{mmol})$ was dissolved in EtOH (22 mL) and acetic acid (12 $\mathrm{mL}$ ). The solution was cooled to $0{ }^{\circ} \mathrm{C}$ and $\mathrm{NaOCl}$ solution (Javel water, commercial solution) was added dropwise over $20 \mathrm{~min}$. The reaction mixture was stirred for $20 \mathrm{~min}$. at $0^{\circ} \mathrm{C}$ and for $5 \mathrm{~h}$ at room temperature. The resulting suspension was diluted with EtOAC (200 mL) and the layers separated. The aqueous layer was twice extracted with EtOAc and the combined organic layers were twice washed with $\mathrm{NaHSO}_{3}$ solution $(7.5 \% \mathrm{v} / \mathrm{v})$ and once with $\mathrm{H}_{2} \mathrm{O}$. These combined aqueous layers were made basic by the addition of $\mathrm{NaHCO}_{3}$ and three times extracted with EtOAc. The combined organic layers were dried $\left(\mathrm{MgSO}_{4}\right)$ and the solvent evaporated. Flash chromatography $\left(\mathrm{SiO}_{2}, \mathrm{EtOAc}\right)$ provided the title compound, 6-Cl-norharmane (420 mg, $2.1 \mathrm{mmol}, 57 \%$ ) as off-white solid. The analytical data matched those reported. 
Figure S-1: Nostocarboline (1), natural sample (CD $\left.\mathrm{CD}_{3} \mathrm{OD}, 300 \mathrm{MHz}\right)$.

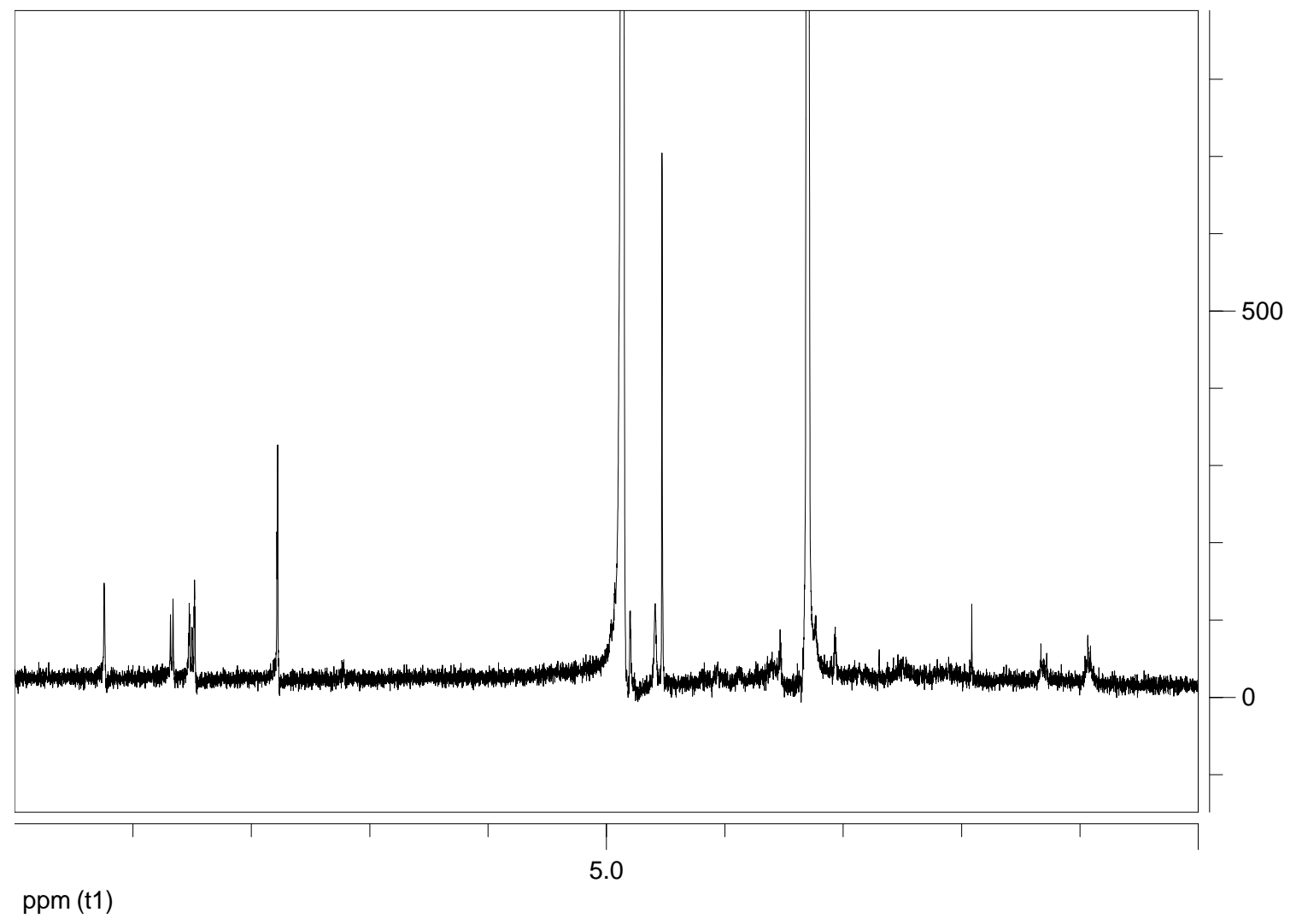


Figure S-2: Nostocarboline iodide (1a), synthetic sample ( $\mathrm{CD}_{3} \mathrm{OD}, 300 \mathrm{MHz}$ ).

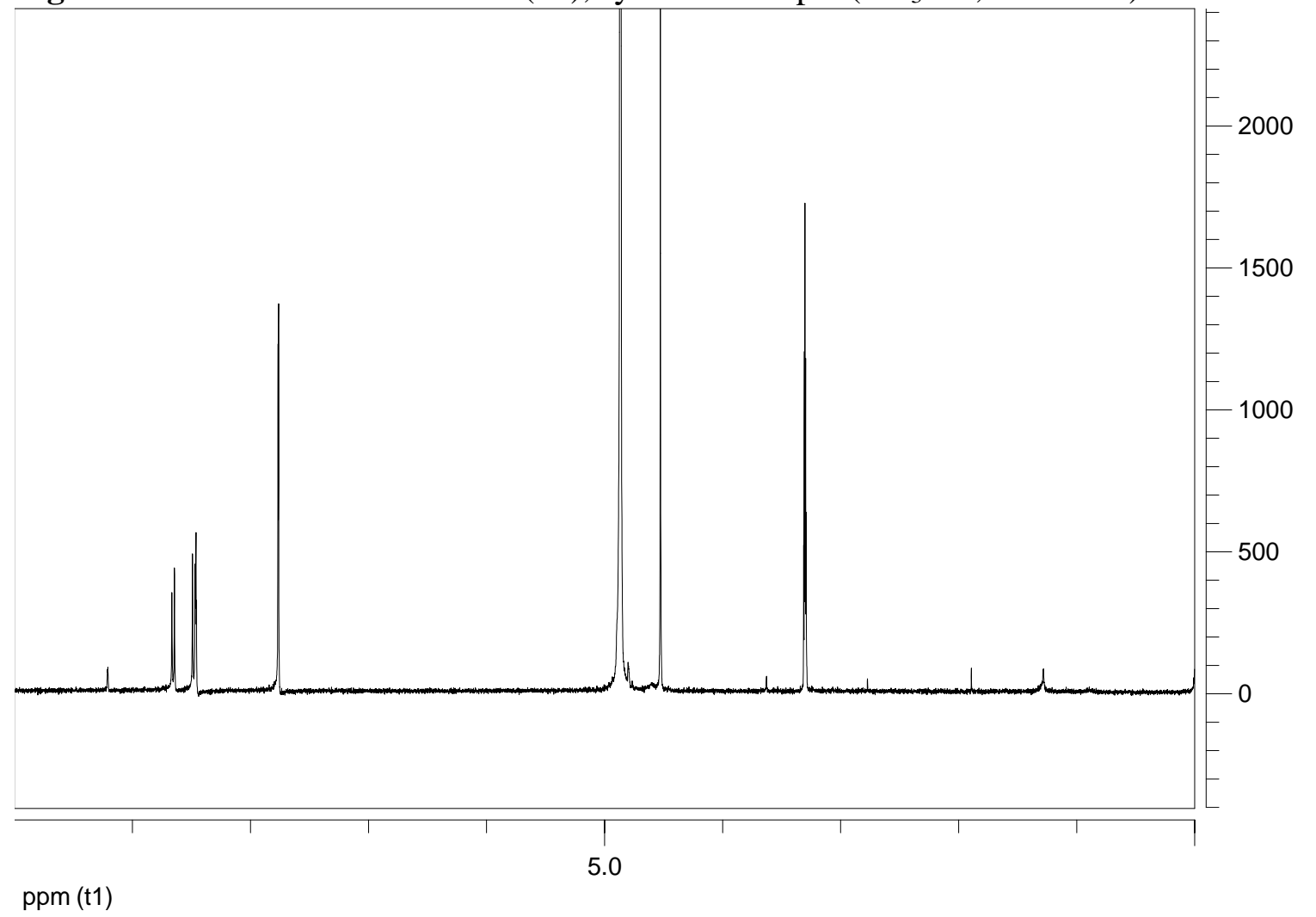


Figure S-3: Nostocarboline, mixture of natural (1) and synthetic (1a) samples $\left(\mathrm{CD}_{3} \mathrm{OD}\right.$, $300 \mathrm{MHz})$.

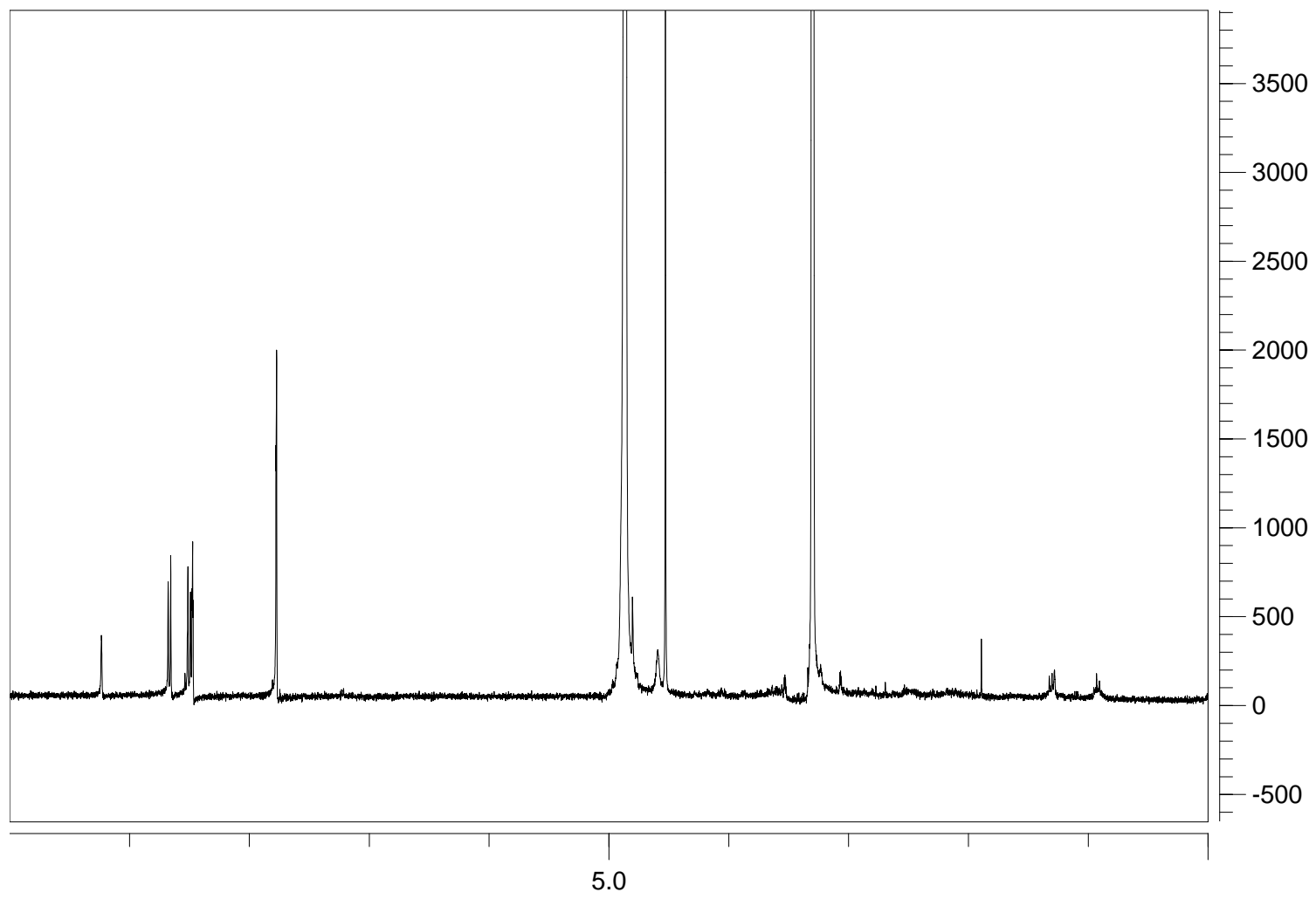

ppm (f1) 
Figure S-4: Nostocarboline (1), natural sample ( $\left.\mathrm{CD}_{3} \mathrm{OD}, 300 \mathrm{MHz}\right)$.

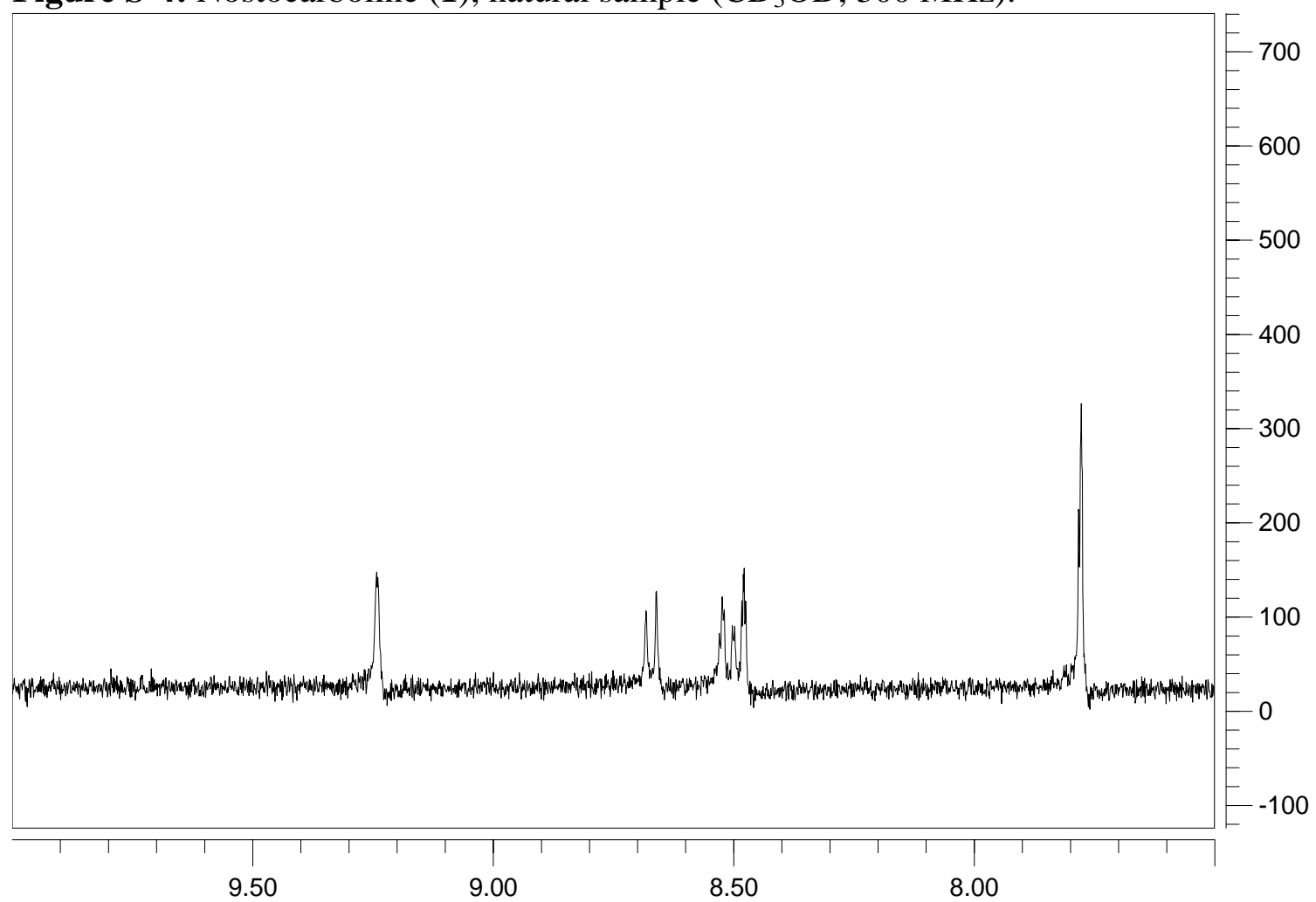
ppm (t1)

Figure S-5: Nostocarboline iodide (1a), synthetic sample $\left(\mathrm{CD}_{3} \mathrm{OD}, 300 \mathrm{MHz}\right)$.

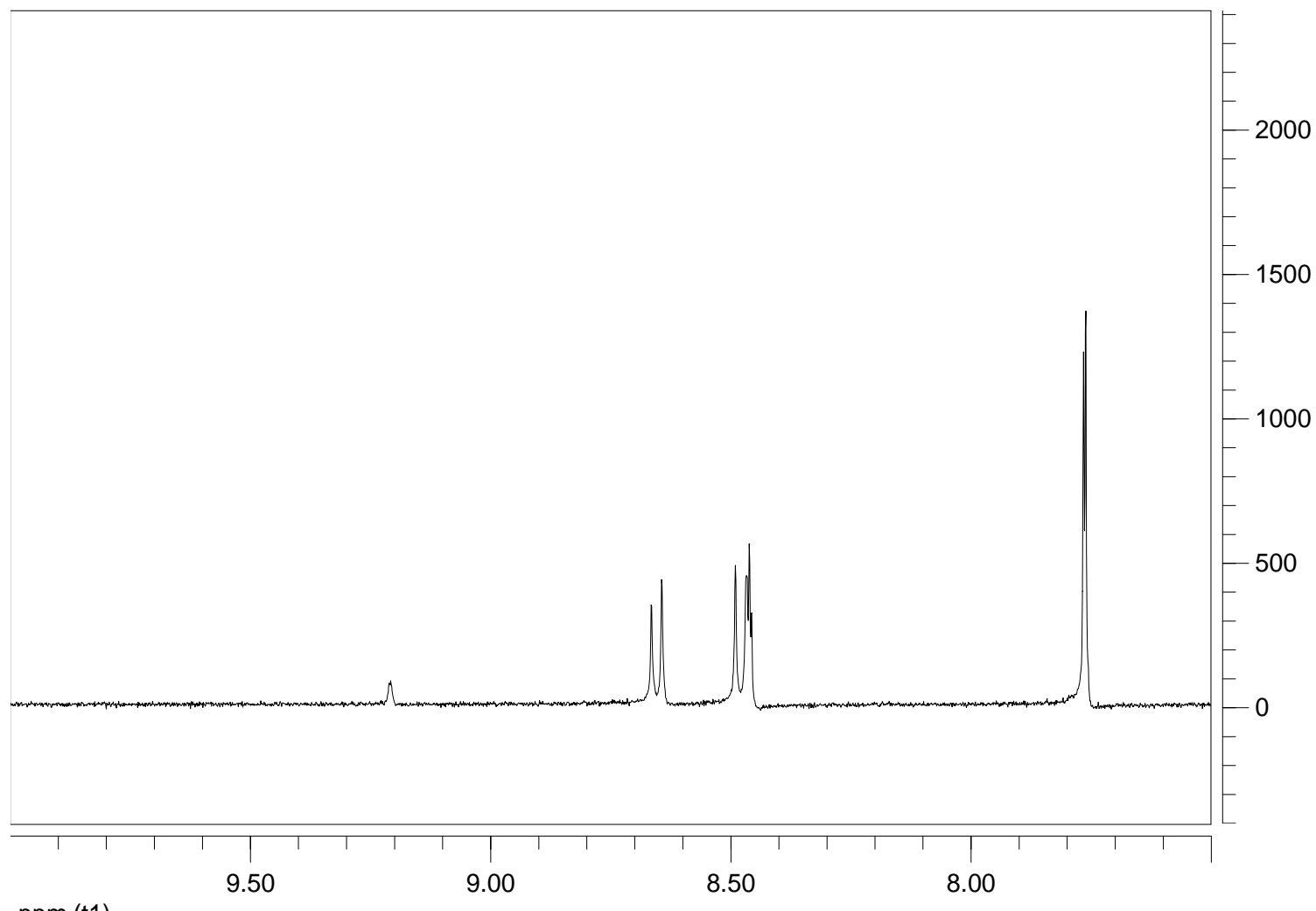

ppm (t1) 
Figure S-6: Nostocarboline iodide, mixture of natural (1) and synthetic (1a) samples $\left(\mathrm{CD}_{3} \mathrm{OD}, 300 \mathrm{MHz}\right)$.

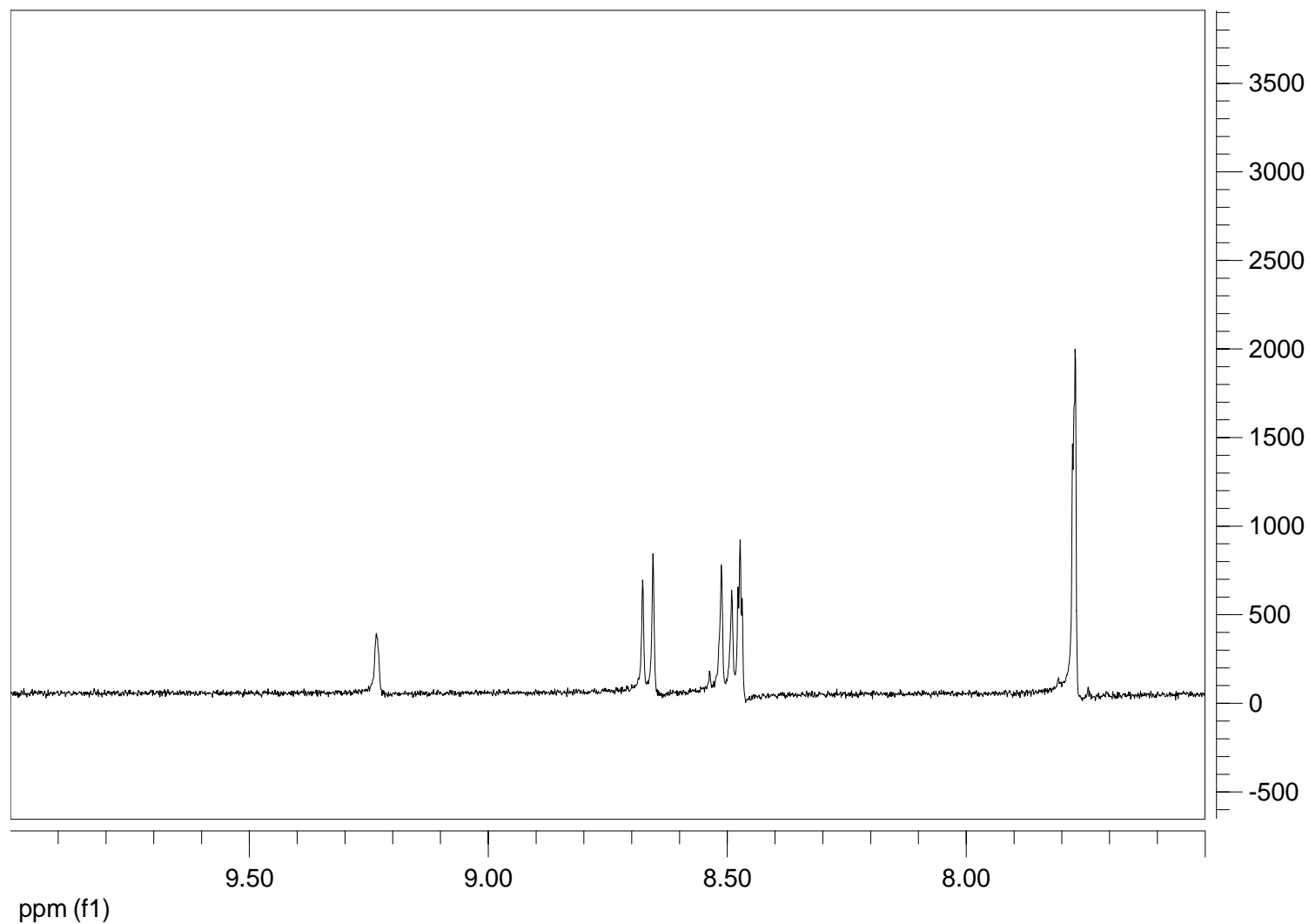


Figure S-7: Nostocarboline iodide (1a), synthetic sample $\left(\mathrm{CD}_{3} \mathrm{OD}, 600 \mathrm{MHz}\right)$. The inset is a part of the HSQC spectrum.

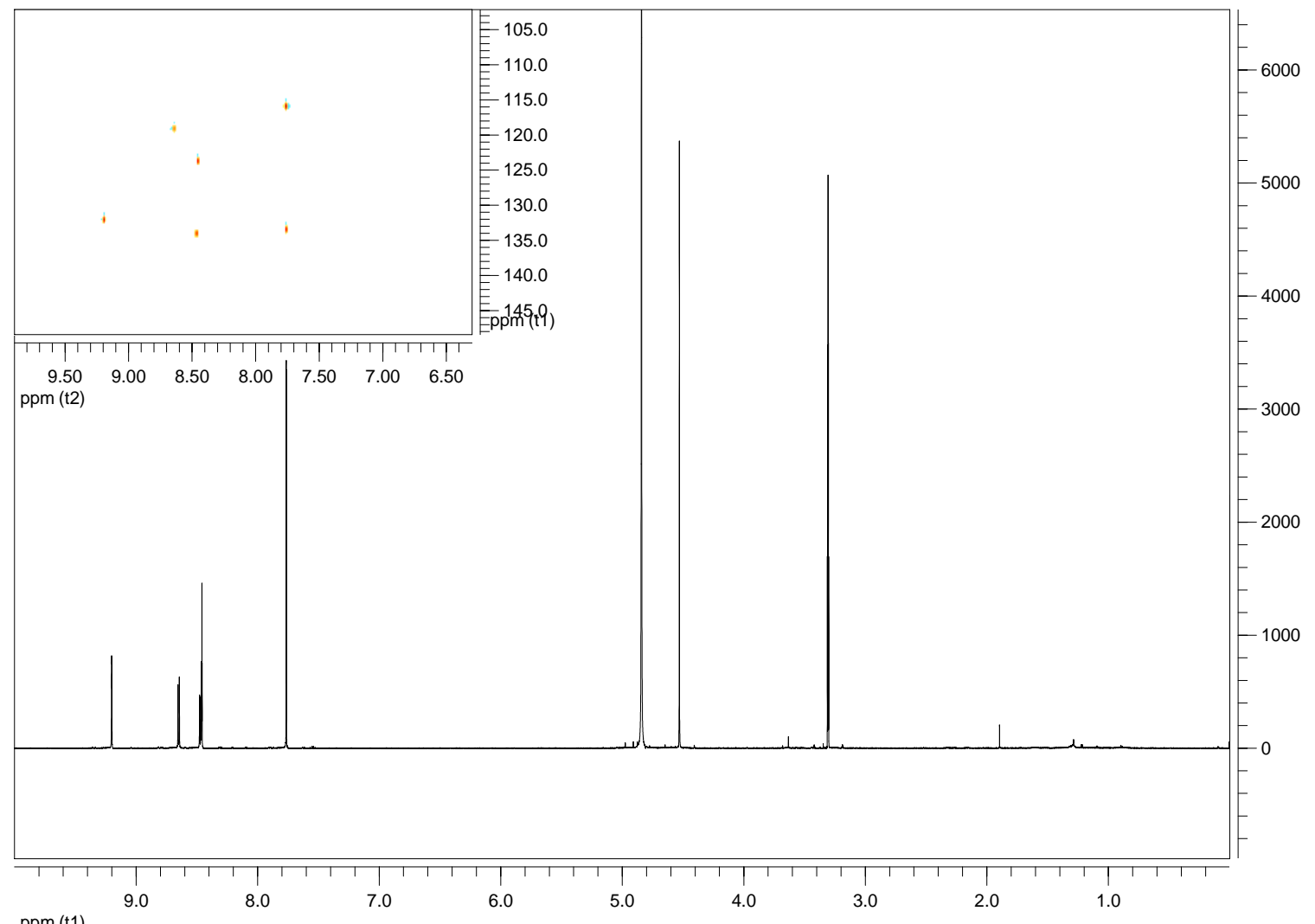

ppm (t1) 